\title{
Subtraction Performances of Primary School Prospective Mathematics Teachers Having Different Cognitive Styles"
}

\author{
Ülkü Ayvaz", Nazan Gündüz, Soner Durmuş, Sefa Dündar \\ Department of Primary Education, Faculty of Education, Abant Izzet Baysal University, Bolu, Turkey
}

Copyright $\bigcirc 2016$ by authors, all rights reserved. Authors agree that this article remains permanently open access under the terms of the Creative Commons Attribution License 4.0 International License

\begin{abstract}
Cognitive styles defined as the way by which individuals prefer to use in order to obtain, edit, utilize, remember the information are discussed as the indication of individual differences in many studies. The study aims to investigate behavioral data of mathematics teacher candidates categorized according to their cognitive styles while they perform subtraction operations with small and big numbers. Participants of the study were 30 teacher candidates, 15 of whom have field-dependent cognitive style while 15 of whom have field-independent cognitive style. Obtained data was analyzed in terms of accuracy and reaction time according to the cognitive style. When it was investigated in terms of accuracy, it was found that there was a significant difference between groups according to only small numbers. In terms of reaction type, however, two groups did not differ in terms of both small and big numbers. Moreover, it is seen that field-dependent participants spent more time while they solve subtraction operations with big numbers.
\end{abstract}

Keywords Cognitive-style, E-Prime, Subtraction, Small-big Numbers

\section{Introduction}

Change of concerns and new opportunities provided by technology have resulted in a new focus about individual differences in research conducted in the field of education. These differences include various variables such as thinking styles, motivation styles, intelligence, and gender. When researches conducted related to individual differences are examined, it is seen that cognitive style is also studied in these researches as a variable.

\subsection{Cognitive Styles}

Cognitive style is defined as the ways that individuals prefer in the process of adapting new knowledge to existing one, evaluating new information and adapting new knowledge to their lives [13]. The model of Witkin, Oltman, Raskin and Karp [24] about field dependence-field independence can be given as an example of cognitive styles. The concepts of field dependence and field independence refer to either one's tendency to outside or his/her independence from outside [21]. Therefore, it is known that field dependent and field independent individuals have different characteristics from each other [9]. According to Jonassen and Grabowski [14], for example, when a field dependent individual is more traditional, more sensitive to others and thinks more holistically, that is, gives less attention to details; a field independent one, on the other hand, can think more analytically, choose independent preferences and therefore $\mathrm{s} / \mathrm{he}$ is the one independent from others. That's why it is probable to obtain different results in the process of investigating these people having different cognitive characteristics. As a matter of fact, it appears in conducted studies that field dependent and independent people reveal different results in terms of investigated variable $[3,4,5,8,26]$.

\subsection{Problem Size Effect in Arithmetic}

It is believed that arithmetic is one of the fields where the individuals with field-dependent and field-independent cognitive styles differ from each other in terms of their cognitive characteristics. Since the field-dependent individuals are traditional and dependent on rules, which is consistent with the routine nature of arithmetic operations, these individuals are expected to be more successful at arithmetic operations.

Arithmetic is defined as a field involving numbers and the relationships between numbers, four operations and calculations based on these operations [18]. According to Van Amerom [23], the concept of number underlies this sub-area of mathematics. Given that number is also a very essential concept in mathematics, the importance of arithmetic becomes more apparent. Furthermore, Swadener and Soedjadi [22] reported that the problems in learning arithmetic would have an adverse impact in learning subsequent concepts since the concepts in mathematics are 
built on each other. For that reason, it is believed that there should be a focus on the studies on arithmetic within the studies on mathematics education.

The review on the studies on arithmetic indicated that one of the current issues is the problem-size effect. These studies, in an attempt to analyze the problem-size effect, classified the numbers in different ranges such as "small" "medium" and "big" or as "smaller" and "big." For instance, the study by Núñez-Peña, Gracia-Bafalluy and Tubau (2011) on the individual differences in arithmetical skills, classified the numbers in the range of 1-4, 6-9 and 16-29 respectively as "small", "medium" and "big" problems. On the other hand, Ashcraft [2] and Dehaene [11] classified the numbers in the range of 1-4 as "small" numbers and those in the range of 6-9 as "big" numbers. It can be stated that such categorization of numbers and analysis on the differences in the process of arithmetic operations with the numbers in different categories followed that the problem-size effect is related to the differences in the solution methods used by individuals [10]. According to LeFevre, Sadesky and Bisanz [17], the problems involving small numbers can be directly solved through retrieval procedures whereas these procedures are not employed in the solution of the problems involving big numbers. In a similar way, Nuez-Pena, Cortinas and Escera [19] as well as Zbrodoff and Logan [25] reported that retrieval methods are used for small numbers while calculation strategies are employed for big numbers. In addition to the strategical differences, Kong, Wang, Shang, Wang, Yang and Zhuang [15], in regard to the problem-size effect, found out that the problems requiring the operations with small numbers are more slowly solved and more error prone than those involving big numbers. In this case, $9+6$ is solved more slowly and more error prone than $3+4$ [25].

The analysis on the studies on the problem-size effect indicated that these studies also compared between different types of operations. In the studies comparing the operations of addition and subtraction, it is reported that the reason that the participants employed procedural knowledge less frequently is that the problem-size effect is greater for the operation of subtraction than for the operation of addition $[7,16]$. Since young adults generally use retrieval procedures in solving the problems related to addition, they prefer to employ numeration and place-value system in the operations of subtraction. It is believed that individuals have a slower reaction time in the problems associated with the operation of subtraction $[17,20]$.

\subsection{Purpose of the Study}

Based on the research, it is observed that reaction time differs in terms of the variables such as accuracy and the use of strategies in relation to the problem-size effect. It is a key concern whether cognitive styles have an impact on the problem-size. Therefore, this study, which is a part of a project supported by a state university, aimed to examine the behavioral data obtained during the operations of subtraction involving big and small numbers performed by the primary school prospective mathematics teachers classified according to their cognitive styles.

\section{Methodology of Research}

\subsection{Research Design}

This study employed a survey method, which is one of the quantitative research methods since it involved the collection of the data in order to determine the certain characteristics of a group [6].

\subsection{Sample of Research}

The participants of the study consisted of a total of 30 primary school prospective mathematics teachers studying in a state university during the spring term of the academic year of 2015-2016. The participants were selected from a total of 198 prospective teachers by means of the application of the Embedded Figures Test developed by Witkin, Oltman, Raskin and Karp [24] through purposive sampling method. In this selection, the formula developed by Alamolhodaei [1] was used; according to the formula, those who scored below the difference between the average score and one-quarter of the standard deviation are classified as low; those who scored above the difference between the average score and one-quarter of the standard deviation are classified as high; and the rest of them are classified as moderate. The low group is identified as "field-dependent" while the high group is found to be "field-independent" (Figure 1). The participants of the study were composed of the fifteen teachers with the lowest scores in the field-dependent group and another fifteen with the highest scores in the field-independent group so that there could be a great cognitive difference among the teachers to participate in the study.

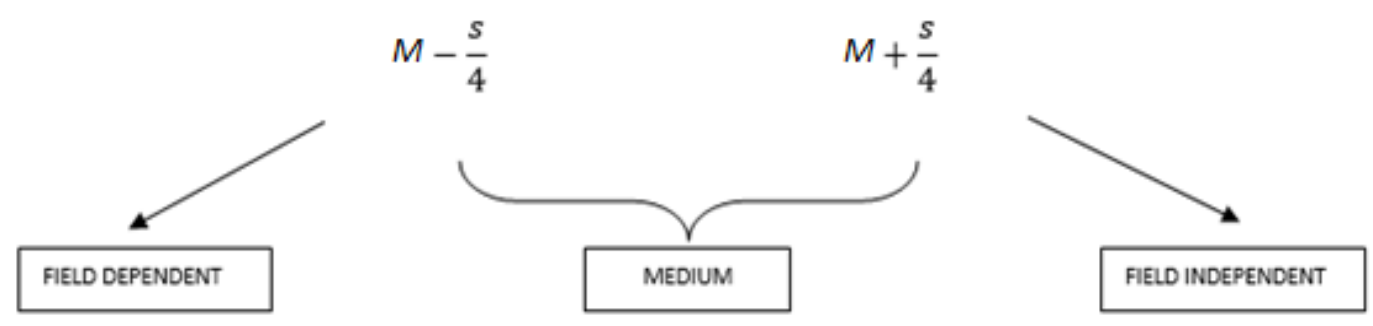

Figure 1. The categorization of the prospective mathematics teachers based on their cognitive styles ( $M$ : Mean, $s$ : standard deviation) 


\subsection{Instrument and Procedures}

The study employed two different tests and one software as the data collection tool. These tools are the Embedded Figures Test, Arithmetic Test and E-Prime Software.

1) Embedded Figures Test: So as to determine the cognitive styles of the participants, the Embedded Figures Test developed by Witkin, Oltman, Raskin and Karp [24] was employed. In the process where the cognitive styles of the prospective teachers are identified, the criteria set by Alamolhodaei [1] were used in accordance with the scores obtained from the test (Figure 1).

2) Arithmetic Test: One of the data collection tools was the Arithmetic Test prepared by the researchers as a result of the review of the studies in the literature. The test involves the operations of subtraction with small numbers, which are between 1-4, and big numbers, which are between 6-9. The operations of subtraction involving the same numbers such as 3-3 were not included in the test. The small and big numbers in the study were determined in consequence of the review of the relevant studies in the literature (for instance, $[2,15,25]$ and the test was prepared accordingly.

3) E-Prime: The final data collection tool in the study was E-Prime software, which was used for creating experiments, gathering the data, and analyzing the obtained data in behavioral studies (http://www.pstnet.com/eprime.cfm). E-Prime is a software which enables researchers to develop paradigms in a great diversity. These paradigms can be randomly or stably presented as an image, text, video or audio. Furthermore, enabling researchers to perform their experiments in various time intervals, the software provides a precise time control. The study employed E-Prime software to present and to record the data of the Arithmetic Test involving the operations of subtraction with small and big numbers developed by the researchers.
The operations of subtraction involving small and big numbers prepared by the researchers by means of E-Prime software were presented to the participants on computer screen in a random order in the soundproofed rooms at a state university. The answers provided by the participants were recorded by E-Prime software. The exercises lasted for approximately 10 minutes for each participant.

\subsection{Data Analysis}

The answers of the participants classified as field-dependent and field-independent based on their cognitive styles in relation to the operations of subtraction in E-Prime software were recorded in terms of their reaction time and accuracy. These data were grouped as the operations with small numbers and those with big numbers. Subsequently, the answers were analyzed in terms of accuracy and the reaction time in accordance with the problem-size effect both in a cognitive style and among cognitive styles. In this process, t-test, Mann-Whitney U and Wilcoxon tests were used.

\section{Results of Research}

The findings of the study are presented below. t-test was performed in order to compare reaction time of subtraction operations involving small and big numbers, which was used by the participants in the same cognitive style group in terms of the problem size effect. The results of the test are indicated in Table 1.

Table 1 demonstrates that the reaction time of subtraction operations involving small and big numbers did not create a significant difference in the field-independent group while there was a significant difference in the field-dependent group in terms of reaction time in accordance with the problem-size effect. The results of the analysis revealed that the field-dependent individuals spend shorter time in solving the operations of subtraction involving small numbers.

Table 1. The comparison of the reaction time of subtraction operations by the field-dependent and field-independent groups in terms of the problem-size effect

\begin{tabular}{cllllllll}
\hline Cognitive Style & Problem-effect Size & $\mathrm{N}$ & $\mathrm{M}$ & $\mathrm{S}$ & $\mathrm{df}$ & $\mathrm{t}$ & $\mathrm{p}$ \\
\hline \multirow{2}{*}{ Field-independent } & Big number & 15 & 1655,11 & 316,86 & & \multirow{2}{*}{14} & \multirow{2}{*}{0,700} & \\
\cline { 2 - 6 } & Small number & 15 & 1640,06 & 291,15 & & & \\
\hline \multirow{2}{*}{ Field-dependent } & Big number & 15 & 1560,12 & 361,42 & \multirow{2}{*}{14} & 2,458 & 0,023 \\
\cline { 2 - 6 } & Small number & 15 & 1449,40 & 439,15 & & & \\
\hline
\end{tabular}


Since analyzed data which was conducted in order to compare the number of correct answers in the solution of the operations of subtraction involving small and big numbers performed by the field-dependent and field-independent individuals were not normally distributed, Wilcoxon test was carried out. The results of the test are presented in Table 2 .

Table 2. The comparison of the operations involving big and small numbers in terms of the number of correct answers

\begin{tabular}{|c|c|c|c|c|c|c|}
\hline Cognitive Style & (Accuracy) & $\mathrm{N}$ & $\begin{array}{l}\text { Mean } \\
\text { Rank }\end{array}$ & $\begin{array}{c}\text { Sum } \\
\text { of } \\
\text { Ranks }\end{array}$ & $\mathrm{Z}$ & $\mathrm{p}$ \\
\hline \multirow{3}{*}{ Field-independent } & $\begin{array}{c}\text { Negative } \\
\text { Ranks }\end{array}$ & 4 & 5,00 & 20,00 & \multirow{3}{*}{$-0,794$} & \multirow{3}{*}{0,427} \\
\hline & $\begin{array}{c}\text { Positive } \\
\text { ranks }\end{array}$ & 6 & 5,83 & 35,00 & & \\
\hline & Ties & 5 & & & & \\
\hline \multirow{3}{*}{ Field-dependent } & $\begin{array}{c}\text { Negative } \\
\text { Ranks }\end{array}$ & 7 & 7 & 49 & \multirow{3}{*}{$-0,254$} & \multirow{3}{*}{0,799} \\
\hline & $\begin{array}{c}\text { Positive } \\
\text { ranks }\end{array}$ & 6 & 7 & 42 & & \\
\hline & Ties & 2 & & & & \\
\hline
\end{tabular}

Table 2 demonstrates that there was not a significant difference in both the field-dependent group and the field-independent group in terms of the numbers of correct answers obtained in subtraction operations involving big and small numbers in accordance with the problem-size effect.

Since the data in the analysis which was conducted in order to compare the number of correct answers provided by the participants in the operations of subtraction involving small and big numbers were not normally distributed, Mann-Whitney U test was carried out. The results of the test are presented in Table 3.

Table 3. The comparison of the number of correct answers to the operations of subtraction involving big and small according to cognitive styles

\begin{tabular}{|c|c|c|c|c|c|c|c|}
\hline $\begin{array}{l}\text { Problem } \\
\text { Size }\end{array}$ & $\begin{array}{l}\text { Cognitive } \\
\text { Style }\end{array}$ & $\mathrm{N}$ & $\begin{array}{l}\text { Mean } \\
\text { Rank }\end{array}$ & $\begin{array}{c}\text { Sum } \\
\text { of } \\
\text { Ranks }\end{array}$ & $\mathrm{df}$ & $\mathrm{U}$ & $\mathrm{p}$ \\
\hline \multirow{2}{*}{$\begin{array}{c}\text { Small } \\
\text { number }\end{array}$} & $\begin{array}{c}\text { Field } \\
\text { independent }\end{array}$ & 15 & 11,73 & 176,00 & \multirow{2}{*}{14} & \multirow{2}{*}{56,00} & \multirow{2}{*}{0,012} \\
\hline & $\begin{array}{c}\text { Field } \\
\text { dependent }\end{array}$ & 15 & 19,27 & 289,00 & & & \\
\hline \multirow{2}{*}{$\begin{array}{c}\text { Big } \\
\text { number }\end{array}$} & $\begin{array}{c}\text { Field } \\
\text { independent }\end{array}$ & 15 & 18,03 & 270,00 & \multirow{2}{*}{14} & \multirow{2}{*}{74,500} & \multirow{2}{*}{0,093} \\
\hline & $\begin{array}{c}\text { Field } \\
\text { dependent }\end{array}$ & 15 & 12,97 & 194,50 & & & \\
\hline
\end{tabular}

Table 3 shows that while there was not a significant difference between two groups in terms of the number of correct answers in the operations of subtraction involving big numbers, the number of correct answers in the operations of subtraction involving small numbers significantly varied according to the cognitive style. The results of the analysis revealed that the field-dependent individuals had more correct answers than the field-independent individuals in the operations of subtraction involving small numbers.

T-test was performed so as to compare the reaction time of subtraction operations involving small and big numbers according to cognitive styles. The results of the test are presented in Table 4.

Table 4. The comparison of the reaction time of subtraction operations involving small and big numbers according to cognitive styles

\begin{tabular}{cccccccc}
\hline $\begin{array}{c}\text { Problem } \\
\text { Size }\end{array}$ & $\begin{array}{c}\text { Cognitive } \\
\text { Style }\end{array}$ & $\mathrm{N}$ & $\mathrm{M}$ & $\mathrm{S}$ & $\mathrm{df}$ & $\mathrm{t}$ & $\mathrm{p}$ \\
\hline \multirow{2}{*}{$\begin{array}{c}\text { Small } \\
\text { number }\end{array}$} & $\begin{array}{c}\text { Field } \\
\text { independent }\end{array}$ & 15 & 1640,06 & 439,15 & & & \\
\cline { 2 - 5 } & $\begin{array}{c}\text { Field } \\
\text { dependent }\end{array}$ & 15 & 1449,40 & 291,15 & $-1,401$ & 0,174 \\
\hline \multirow{2}{*}{$\begin{array}{c}\text { Big } \\
\text { number }\end{array}$} & $\begin{array}{c}\text { Field } \\
\text { independent }\end{array}$ & 15 & 1655,11 & 316,86 & & & \\
\cline { 2 - 5 } & $\begin{array}{c}\text { Field } \\
\text { dependent }\end{array}$ & 15 & 1560,12 & 194,00 & $-0,765$ & 0,450 \\
\hline
\end{tabular}

Table 4 demonstrates that there was not a significant difference in regard to cognitive styles in the operations of subtraction involving both big and small numbers in terms of reaction time.

\section{Discussion}

This study aims to examine the impact of cognitive styles in the process where the operations of subtraction involving small and big numbers are solved by primary school prospective mathematics teachers. The results obtained were evaluated in terms of the number of correct answers and the reaction time based on cognitive styles. The results of the study revealed that there was not a difference among the field-independent individuals in the operations of subtraction involving big and small numbers although there was a significant difference in the field-dependent individuals in favor of the small numbers. In other words, it means that the operations of subtraction involving small numbers are solved by these field-dependent individuals in a shorter time. The reason may be that the prospective teachers employed retrieval strategies in the operations involving small numbers. Moreover, significant difference was not found in both the field-dependent and field-independent groups in terms of the number of correct answers in the subtraction operations involving small and big numbers. Indeed, the two groups had a similar number of correct answers, which may originate from that arithmetic operations do not require a heavy cognitive load and the participants are prospective mathematics teachers, who are, therefore, proficient in the study area.

In regard to the numbers of correct answers in the operations of subtraction according cognitive style, while there was not a significant difference in big numbers in terms of cognitive styles, there a significant difference was obtained in the operations of subtraction involving small numbers in favor of the field-dependent individuals. The higher number of correct answers obtained by the field-dependent individuals may result from that they might be able to gather their attention in a better way due to the nature of their cognitive styles $[12,14]$ and that the questions are provided in a symbolic representation. When the reaction time of subtraction operations involving small and big 
numbers was compared based on the cognitive styles, there a significant difference was not found between the field-dependent and field-independent cognitive styles. As mentioned in the literature, it is expected that there should be a difference in the reason that retrieval techniques are preferred in the operations involving small numbers and calculation strategies are preferred in the operations involving big numbers $[19,25]$ in terms of the reaction time in accordance with the problem-size effect. However, in regard to the operation of subtraction, the reason that the participants solved the operations in a similar time frame may be that counting and multi-step procedures were used both in the operations of subtraction involving small and big numbers $[17,20]$.

Based on the research, it is observed that reaction time differs in terms of the variables such as accuracy and the use of strategies in relation to the problem-size effect. It is a key concern whether cognitive styles have an impact on the problem-size. Therefore, this study, which is a part of a project supported by a state university, aimed to examine the behavioral data obtained during the operations of subtraction involving big and small numbers performed by the primary school prospective mathematics teachers classified according to their cognitive styles.

\section{Conclusions}

Although various neuroscience studies has been conducted in the area of mathematics education to understand the neural bases of mathematics, such studies are quite new for Turkey. While studies examining problem size effect are not directly related with neural bases of mathematics, it can be said that these are subcategories of neuroscience studies. Therefore, the problem size effect studies are also important for neuroscience studies in education. Moreover, these studies come into prominence with providing insight for mental structure of mathematics education and developing teaching strategies according to these mental structures. From this point of view, this study is thought to be important in terms of being a pioneer study in Turkey.

\section{Acknowledgements}

This study was conducted in the scope of the Scientific Research Project Department of Abant Izzet Baysal University with the project number 2015.2.4.930.

\section{Note}

*The abstract of this paper was presented at 2nd International Conference on Lifelong Learning and Leadership for All (ICLEL-16), in Liepaja on July, 21-23, 2016.

\section{REFERENCES}

[1] Alamolhodaei, H. (1996). A study in higher education calculus and students' learning styles. (Unpublished doctoral dissertation). University of Glasgow, England.

[2] Ashcraft, M. H., (1992).Cognitive arithmetic: A review of data and theory. Cognition 44, 76-106.

[3] Ates, S., \& Cataloglu, E. (2007). The effects of students' cognitive styles on conceptual understandings and problemsolving skills in introductory mechanics. Research in Science \& Technological Education, 25(2), 167-178.

[4] Bahar, M. (1999). Investigation of biology students' cognitive structure through word association tests, mind maps and structural communication grids. (Unpublished doctoral dissertation). University of Glasgow, England.

[5] Bahar, M. (2003). The effects of motivational styles on group work and discussion-based seminars. Scandinavian Journal of Educational Research, 47(4), 461- 473.

[6] Büyüköztürk, Ş., Kılıç E., Akgün Ö. E., Karadeniz, Ş. ve Demirel, E. (2009). Scientific research methods. Ankara: Pegem Yayıncılık.

[7] Campbell, J. I., \& Xue, Q. (2001). Cognitive arithmetic across cultures. Journal of Experimental Psychology: General, 130(2), 299.

[8] Çataloglu, E. \& Ates, S. (2014). The effects of cognitive styles on naïve impetus theory application of pre-service science Teachers, International Journal of Science and Mathematics Education, 12(4), 699-719.

[9] Coffey, J. W. ve Canas A. J. (2001). Proceedings of 19th International Conference On Technology and Education: An advance organizer approach to distance learning course presentation. Florida, USA.

[10] Das, R., LeFevre, J. A., \& Penner-Wilger, M. (2010). Negative numbers in simple arithmetic. The Quarterly Journal of Experimental Psychology, 63(10), 1943-1952.

[11] Dehaene, S. (1992). Varieties of numerical abilities. Cognition, 44(12), 1-42.

[12] Güven, B. (2003). The impact of educational activities prepared in accordance with the dimensions of the field-dependency and field-independency cognitive styles in the $5^{\text {th }}$ grade course of social studies in elementary education on academic achievement and attitudes. (Unpublished doctoral dissertation). Anadolu University, Turkey.

[13] Hayes, J., \& Allinson, C.W. (1998). Cognitive style and the theory and practice of individual and collective learning in organizations. Human Relations, 51, 847-871.

[14] Jonassen, D. H., \& Grabowski, B. (1993). Individual differences and instruction. New York: Allen \& Bacon.

[15] Kong, J., Wang, Y., Shang, H., Wang, Y., Yang, X., \& Zhuang, D. (1999). Brain potentials during mental arithmetic-effects of problem difficulty on event-related brain potentials. Neuroscience Letters, 260(3), 169-172.

[16] LeFevre, J. A., DeStefano, D., Penner-Wilger, M., \& Daley, K. 
E. (2006). Selection of procedures in mental subtraction. Canadian Journal of Experimental Psychology/Revue canadienne de psychologie expérimentale, 60(3), 209.

[17] LeFevre, J. A., Sadesky, G. S., \& Bisanz, J. (1996). Selection of procedures in mental addition: Reassessing the problem size effect in adults. Journal of Experimental Psychology: Learning, Memory, and Cognition, 22(1), 216.

[18] National Council of Teachers of Mathematics. (1991). Professional standards for teaching mathematics. Reston, VA: The National Council of Teachers of Mathematics.

[19] Núñez-Peña, M. I., Cortiñas, M., \& Escera, C. (2006). Problem size effect and processing strategies in mental arithmetic. Neuroreport, 17(4), 357-360.

[20] Seyler, D. J., Kirk, E. P., \& Ashcraft, M. H. (2003). Elementary subtraction. Journal of Experimental Psychology: Learning, Memory, and Cognition, 29(6), 1339.

[21] Somyürek, S. ve Yalın, H. İ. (2007). The impact of organizers used in computer-assisted educational software on the academic achievement of field-dependent and field-independent students. Türk Eğitim Bilimleri Dergisi. 5(4), 587-607.

[22] Swadener, M. \& Soedjadi, R. (1988). Values, mathematics education and the task of developing pupils' personalities: An Indonesian perspective. Educational Studies in Mathematics, 19(2), 193-208.

[23] Van Amerom, B. (2002). Reinvention of early algebra: Developmental research on the transition from arithmetic to algebra. (Unpublished doctoral dissertation). University of Utrecht, Netherlands.

[24] Witkin, H. A., Oltman, P. K., Raskin, E., \& Karp, S. A. (1971). The group embedded figures test. Palo Alto, CA: Consulting Psychological Press.

[25] Zbrodoff, N. J., \& Logan, G. D. (2000). Whenit hurts to be misled: A Stroop-like effect in a simple addition production task. Memory \& Cognition, 28(1), 1-7.

[26] Riding, R. J., \& Cheema, I. (1991). Cognitive styles-an overview and integration. Educational Psychology, 11(3 and 4), 193-215. 